DEPÓSITO LEGAL ZU2020000153

Esta publicación científica en formato digital

es continuidad de la revista impresa

ISSN 0041-8811

E-ISSN 2665-0428

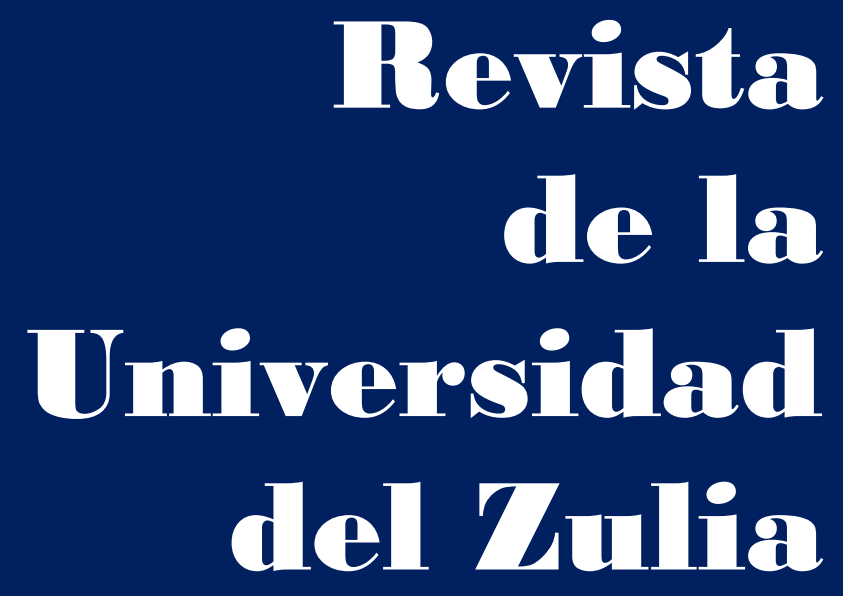

Fundada en 1947

por el Dr. Jesús Emrique Lossada

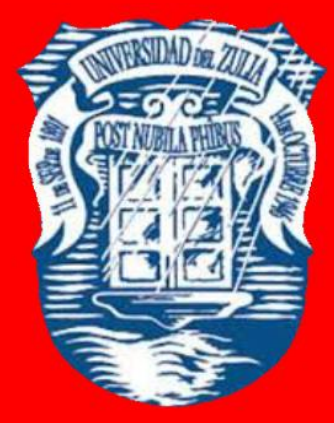

Ciencias

Sociales

y Arte

Año $12 \quad N^{\circ} 34$

Septiembre - Diciembre 2021

Tercera Época

Maracaibo-Veneruela 


\title{
Propuesta de estrategias de marketing para mejorar el consumo de café
}

\author{
Abel Salcedo Herrera * \\ Carlos Rios-Campos ** \\ Ítalo Maldonado Ramirez $* * *$ \\ Henry Agreda Cerna **** \\ Wilfredo Ruiz Camacho *****
}

RESUMEN

El artículo propone estrategias de marketing para mejorar el consumo de café en el distrito de ChotaPerú, para lo cual se realizó un estudio de mercado, a objeto de diagnosticar el consumo. Estudio de tipo descriptivo, propositivo, no experimental, transversal. Dentro de los principales resultados se tiene que: el $41 \%$ de los encuestados prefieren la marca Nescafé; un 43\% están dispuestos a pagar de S/.1.50 a S/.2.00; el 65\% toman café en su casa; y el 47\% prefieren informarse a través de la televisión sobre los beneficios que brinda el café. Se concluyó que el consumo de café muestra signos claros de crecimiento; las estrategias de marketing necesitan ser efectuadas bajo una excelente coordinación, tanto del gobierno como de las empresas del rubro. De esta manera se beneficiarán más de 250,000 familias que viven de la caficultura a nivel nacional, mejorando su calidad de vida con mayores ingresos económicos, y generando nuevos puestos de trabajo.

PALABRAS CLAVE: mercado; marketing; café; economía agraria.

* Licenciado en Administración. Articulador comercial - Avanza Rural. Chota -Perú. ORCID: https://orcid.org/0000-0001-8454-0247. Email: absahh@hotmail.com

** Investigador Concytec - RENACYT. Doctor en Gestión Universitaria. Maestro en Administración. Docente de la Universidad Nacional Toribio Rodríguez de Mendoza de Amazonas. Bagua -Perú. ORCID: https://orcid.org/0000-0001-8003-5577. E-mail: carlos.rios@untrm.edu.pe

*** Decano de la Facultad de Ingeniería de Sistemas y Mecánica Eléctrica. Doctor en Administracion de la Educación. Universidad Nacional Toribio Rodríguez de Mendoza de Amazonas. Bagua -Perú. ORCID: https://orcid.org/0000-0002-3147-3519. E-mail: italo.maldonado@untrm.edu.pe

**** Docente Asociado. Maestro en Administración de la Educación. Universidad Nacional José María Arguedas. Andahuaylas-Perú. ORCID: https://orcid.org/0000-0003-0253-1588. E-mail: hwagredacerna@gmail.com

***** Docente Asociado. Maestro en Producción Agrícola. Ingeniero Agrónomo. Universidad Nacional de Jaén, Jaén-Perú. ORCID: https://orcid.org/0000-0003-1917-3625. E-mail: wilfredo.ruiz@unj.edu.pe

Recibido: 19/05/2021

Aceptado: 14/07/2021 


\section{Proposal of marketing strategies to improve coffee consumption}

ABSTRACT

The article proposes marketing strategies to improve coffee consumption in the district of Chota-Peru, for which a market study was carried out, in order to diagnose consumption. Descriptive, purposeful, non-experimental, cross-sectional study. Among the main results are that: $41 \%$ of those surveyed prefer the Nescafé brand; $43 \%$ are willing to pay from S / .1.50 to S / .2.00; $65 \%$ drink coffee at home; and $47 \%$ prefer to learn from television about the benefits of coffee. It was concluded that coffee consumption shows clear signs of growth; Marketing strategies need to be carried out under excellent coordination, both from the government and from the companies in the field. In this way, more than 250,000 families that live from coffee growing nationwide will benefit, improving their quality of life with higher economic income, and generating new jobs.

KEY WORDS: market; marketing; coffee; agrarian economy.

\section{Introducción}

Reuters (2016) afirma que Brasil es uno de los países de mayor producción y consumo de café en el mundo, con tendencias en años anteriores de superar a los Estados Unidos, un país de gran consumo de café.

La Federación Nacional de Café en Colombia (2016) manifiesta que en este país, el consumo de café está por debajo de Brasil. Por lo que lanzó su programa "Toma Café"; el plan viene operando desde marzo de 2010, como estrategia para incrementar el consumo doméstico.

Rodríguez (2016) sostiene que en Costa Rica, la producción de café ha ido aumentando gradualmente, en función de la oferta y la demanda; mientras que el consumo crece a una tasa más moderada, similar al crecimiento de la población.

Minagri (2016) plantea que en el Perú no se nota un incremento referente al consumo de café; para lo cual propone que, entre 2016-2017, se lanzarán al menos seis grandes campañas que promoverán el consumo interno de café, tanto en grandes ferias como en supermercados, colegios y empresas, con el fin de mejorar su consumo. 
La Junta Nacional del Café (2016) indica que en el Perú el consumo per cápita de este grano es de sólo 600 gramos al año, cantidad que está por debajo del que se tiene en Colombia y Brasil. Esto se debe a que hemos sufrido embates de plagas y repercusiones climatológicas; la endemia más grande y terrible fue la roya amarilla que terminó con los cafetales; por ello, la Junta Nacional del Café, en acuerdo con el Ministerio de Agricultura y empresas privadas del rubro, proponen plantear estrategias para mejorar el consumo de café.

Según Cruz (2018) la propuesta pertenece a la empresa en la que se realizó la investigación, y es posible adaptarla a organizaciones que ofrezcan un servicio, que presenten la situación estudiada. Perea \& Rivas (2008) afirman que los productores poseen estrategias de diferenciación a la altura de la competencia local y mundial. En efecto, "a los pequeños productores y al campesinado les favorecen prácticas alternativas que desafían la hegemonía del capitalismo exportador, tales como la agroecología” (Hernández y Hurtado, 2020), y el impulso de la comercialización de sus rubros tradicionales.

En el distrito de Chota, en la región Cajamarca - Perú, a pesar de ser un lugar con un clima adecuado para el consumo de bebidas calientes y energizantes como el café, éste no se constituye como una de las bebidas preferidas de la población, a pesar de contar con algunas cafeterías en el distrito y plantaciones de cafetales ubicadas en la mayoría de distritos aledaños a la provincia, que producen café de muy buena calidad.

El problema planteado en este trabajo fue, ¿Qué estrategias de marketing se pueden utilizar para mejorar el consumo de café en el distrito de Chota?

El objetivo general consiste en proponer estrategias de marketing para mejorar el consumo de café en distrito de Chota.

\section{Aspectos teóricos}

Salazar (2004) en su trabajo de estrategia empresarial, cita a Michael Porter, donde menciona que, la esencia de la estrategia es elegir una posición única y valiosa basada en sistemas de actividades; estrategia es un término utilizado desde siglos pasados es decir desde la primera guerra mundial; Porter menciona que el mundo, las industrias, y todo lo que se emprende debe hacerse en función a estrategias, porque siempre va existir un competidor, o algún obstáculo en 
Abel Salcedo Herrera et al. /// Propuesta de estrategias de marketing para mejorar el consumo de café, 76-96 DOI: http://dx.doi.org/10.46925//rdluz.34.06

el camino empresarial, y ante ello deben trazar estrategias, con el fin de lograr determinados objetivos.

Kotler (2006) señala que el buen marketing no es fruto del azar, sino de una planeación y ejecución minuciosa. Las prácticas de marketing se ajustan y se reformulan de manera constante en todas las industrias para aumentar la posibilidad de éxito. Son de suma importancia las estrategias de marketing, y una herramienta importante es el marketing mix. Sin embargo, la excelencia no es frecuente dentro del marketing y alcanzarla resulta muy complicado. El marketing es tanto un arte como una ciencia, por lo que existe una tensión constante entre la teoría del marketing y su parte creativa.

Para Espinoza (2015) el diseño de las estrategias de marketing es uno de los principales aspectos a trabajar dentro del campo empresarial. Las estrategias de marketing definen cómo se van a conseguir los objetivos comerciales de una empresa. Para ello es necesario identificar y priorizar aquellos productos que tengan un mayor potencial y rentabilidad, seleccionar el público que será atendido, definir el posicionamiento de marca que se desea impulsar en la mente de los clientes, y trabajar de forma estratégica las diferentes variables que forman el marketing mix.

García (2010) indica que el consumo se puede entender con teorías que lo abordan desde diferentes perspectivas, como son: la economía, la política, la antropología y la sociología. Sin embargo, no existe una teoría sociocultural que lo explique. El autor cita a Manuel Castells, quien menciona que el consumo "es un sitio donde los conflictos entre clases, originados por la desigual participación en la estructura productiva, se continúan a propósito de la distribución y apropiación de los bienes".

Según Ruiz (2002), el café es una bebida que se obtiene por infusión de los granos tostados y molidos del árbol del cafeto (coffea arábica); es oriundo de Arabia, desde donde se esparció a todo el Oriente, y siglos después a través de Europa a todo el mundo. Existen dos especies de café: la especie arábica y la robusta.

Para Castañeda (2000), el grupo de variedades cultivadas en el Perú derivan de la especie Coffea arábica, catalogándose en el mundo cafetalero como "otros suaves", caracterizados por su fina calidad, excelente aroma y sabor. Entre sus variables están: el Typica, el Bourbón, el Catuai, el Pache, el Caturra y el Catimor. Debido a las condiciones geográficas y climáticas, se cultiva 
entre los 1000 a 1800 msnm, zona caracterizada por lluvias altas, baja luminosidad, con una temperatura media anual de 12 a $20^{\circ} \mathrm{C}$, que permite producir un café de excelente calidad.

En el Perú existen marcas de café tostado molido y en grano, así como de café soluble que se comercializan a través de supermercados, mercados, bodegas y autoservicios. Las marcas de café tostados más comunes son: Cafetal, Altomayo, Cocla, Mountain Villa Rica, Zena, Britt y Monarca. En cafés solubles o instantáneos, las más conocidas son: Nescafé, Altomayo, Mónaco, Don Café y marcas propias de los principales supermercados como: Wong, Metro y Bells.

\section{Metodología}

El estudio fue de tipo descriptivo, propositivo, no experimental, transversal. Las técnicas e instrumentos de la investigación fueron una encuesta dirigida a la población del distrito de Chota y una entrevista dirigida a las principales cafeterías del distrito. La metodología utilizada se muestra en la Tabla l:

Tabla l. Metodología

\begin{tabular}{ccc}
\hline Objetivos específicos & Metodología & Autor \\
\hline $\begin{array}{c}\text { Diagnosticar el consumo } \\
\text { de café en el distrito de } \\
\text { Chota. }\end{array}$ & $\begin{array}{c}\text { Aplicación de encuestas y } \\
\text { entrevistas. }\end{array}$ & $\begin{array}{c}\text { Naupas (2013) y } \\
\text { Ñaupas (2013). }\end{array}$ \\
\hline $\begin{array}{c}\text { Elaborar estrategias de } \\
\text { Marketing para mejorar el } \\
\text { consumo de café en el } \\
\text { distrito de Chota. }\end{array}$ & $\begin{array}{c}\text { Elaborar una matriz } \\
\text { FODA y Desarrollar } \\
\text { ealidar la propuesta. }\end{array}$ & $\begin{array}{c}\text { Espinoza, (2015) y } \\
\text { Ansoff, (1957). }\end{array}$ \\
& Mediante un experto en & Lili Díaz Manosalva \\
& Administración & \\
\hline
\end{tabular}

Fuente: Elaboración propia.

La población se describe a continuación en las Tablas 2 y 3. 
Tabla 2. Descripción de la población

\begin{tabular}{|c|c|}
\hline Población & Descripción \\
\hline Población Total & $\begin{array}{l}\text { El mercado total será toda la población del distrito } \\
\text { de Chota. }\end{array}$ \\
\hline Población Potencial & $\begin{array}{l}\text { El mercado potencial estará determinado por todas } \\
\text { las personas interesadas en consumir café, que } \\
\text { representa el } 64 \% \text { de la población según INEI, } 2015 \text {. }\end{array}$ \\
\hline Población Disponible & $\begin{array}{l}\text { Personas que tienen el acceso y el interés de } \\
\text { consumir café, con nivel socioeconómico baja, media } \\
\text { y alta, representando el } 80 \% \text { de la población } \\
\text { potencial. }\end{array}$ \\
\hline $\begin{array}{l}\text { Población Disponible } \\
\text { Calificado }\end{array}$ & $\begin{array}{l}\text { Está representado por las personas con capacidad de } \\
\text { consumir café, que viene a ser el } 90 \% \text { de la población } \\
\text { disponible. }\end{array}$ \\
\hline Mercado Ocupado & $\begin{array}{l}\text { Es igual a la población disponible calificada porque } \\
\text { no se ha insertado un producto nuevo al mercado. }\end{array}$ \\
\hline Mercado meta & $\begin{array}{l}\text { Estará representado por las personas del distrito de } \\
\text { Chota que tengan interés, acceso y capacidad de } \\
\text { consumir café en el distrito. }\end{array}$ \\
\hline
\end{tabular}

Fuente: Elaboración propia.

Tabla 3. Segmentación de la población

\begin{tabular}{lll}
\hline ITEM & Descripción & Población \\
\hline A & Población Total & 48698 \\
\hline B & Población Potencial & 31137 \\
\hline C & Población Disponible & 24905 \\
\hline D & Población Disponible Calificado & 22440 \\
\hline E & Población Ocupada & 22440 \\
\hline F & Población meta $=\mathrm{n}$. & 22440
\end{tabular}

Fuente: Elaboración propia. 
3. Resultados

3.1. Objetivo específico 1: Diagnosticar el consumo de café en el distrito de Chota.

Gráfico 1. Sexo de los encuestados

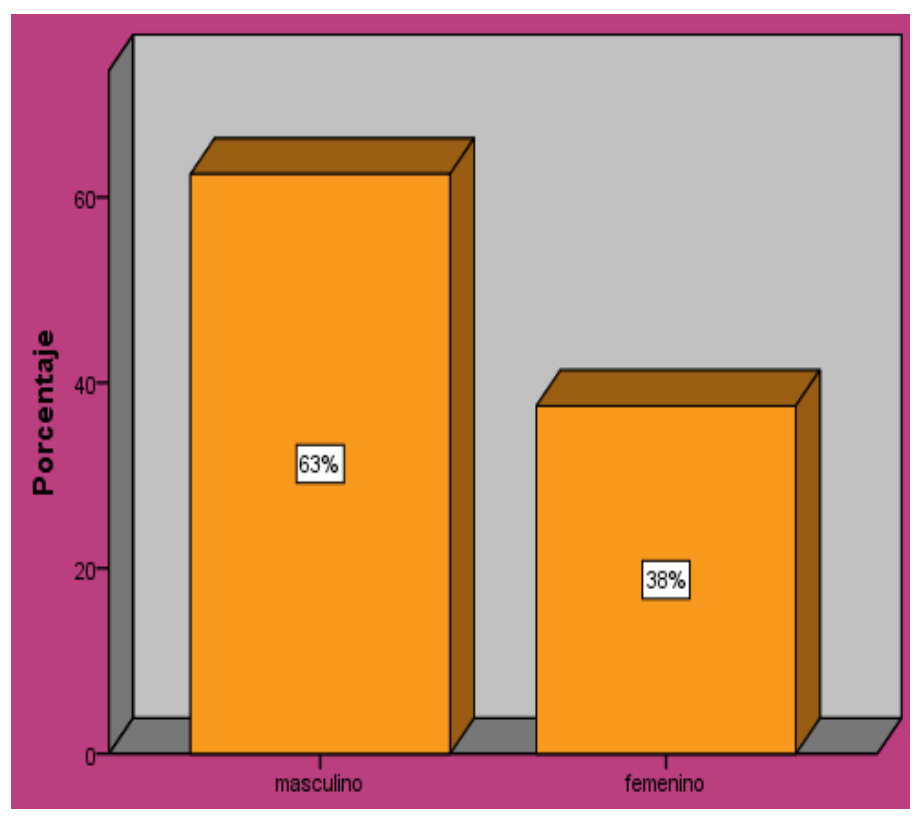

Fuente: Elaboración propia.

Interpretación: De las 362 personas encuestadas, el 63\% son varones, es decir 228 personas: y 134 personas son mujeres, que representa el 38\% del total.

\section{Gráfico 2. Edad de los encuestados}

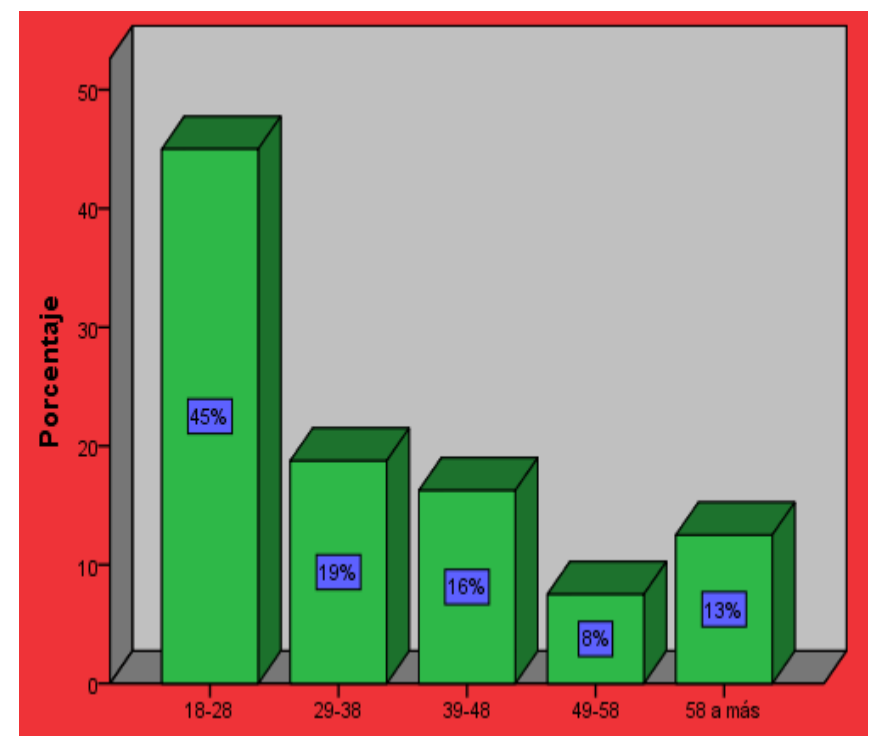

Fuente: Elaboración propia. 
Interpretación: Del 100\% de encuestados o de 362 encuestas, el 45\% lo conforman las personas que están entre las edades de 18 años hasta 28 años; en el 16\% se encuentran las personas entre 29 a 38 años; el 8\% son aquellas personas de 49 a 59 años; y el 13\% lo conforman las personas encuestadas, entre las edades de 58 años a más.

\section{Gráfico 3. Ocupación de los encuestados}

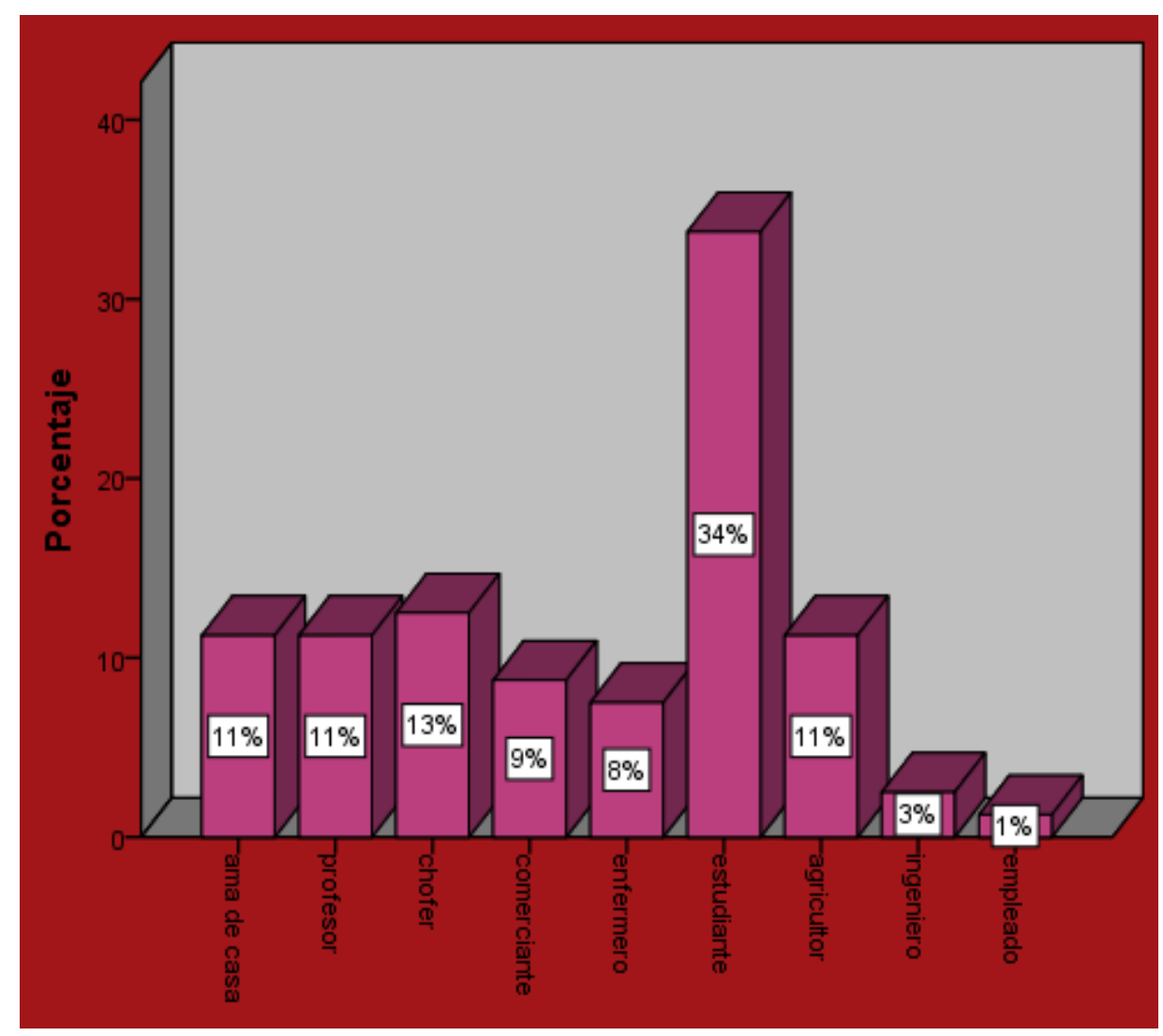

Fuente: Elaboración propia.

Interpretación: Haciendo una indagación sobre la ocupación de las personas encuestadas, respondieron lo siguiente: Un $11 \%$ manifestaron que son amas de casa, $11 \%$ se dedican al trabajo de profesor, $13 \%$ cumplen la labor de choferes, $9 \%$ son comerciantes, $8 \%$ de los encuestados trabajan como enfermeros; el 34\% son estudiantes, un $11 \%$ se ocupan en la agricultura; y 3\%, 1\%, respectivamente, ejercen la labor de ingeniero y de empleado, conformando de esta manera el 100\% de personas encuesta 
Gráfico 4. ¿Usted toma café?

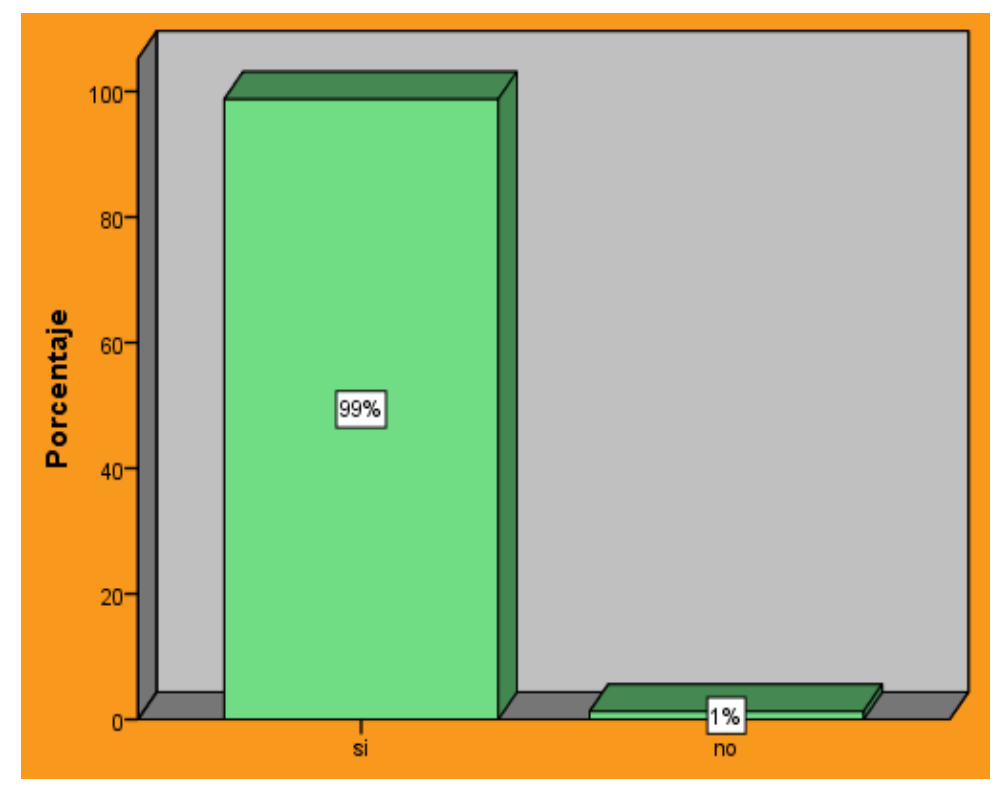

Fuente: Elaboración propia.

Interpretación: Cuando se les preguntó a las personas encuestadas si toman café: El 99\% respondieron que sí, los cuales representan 358 personas encuestadas; y 4 personas manifestaron que no tomaban café, los cuales representan el 1\% del total.

\section{Gráfico 5. Beneficios del café}

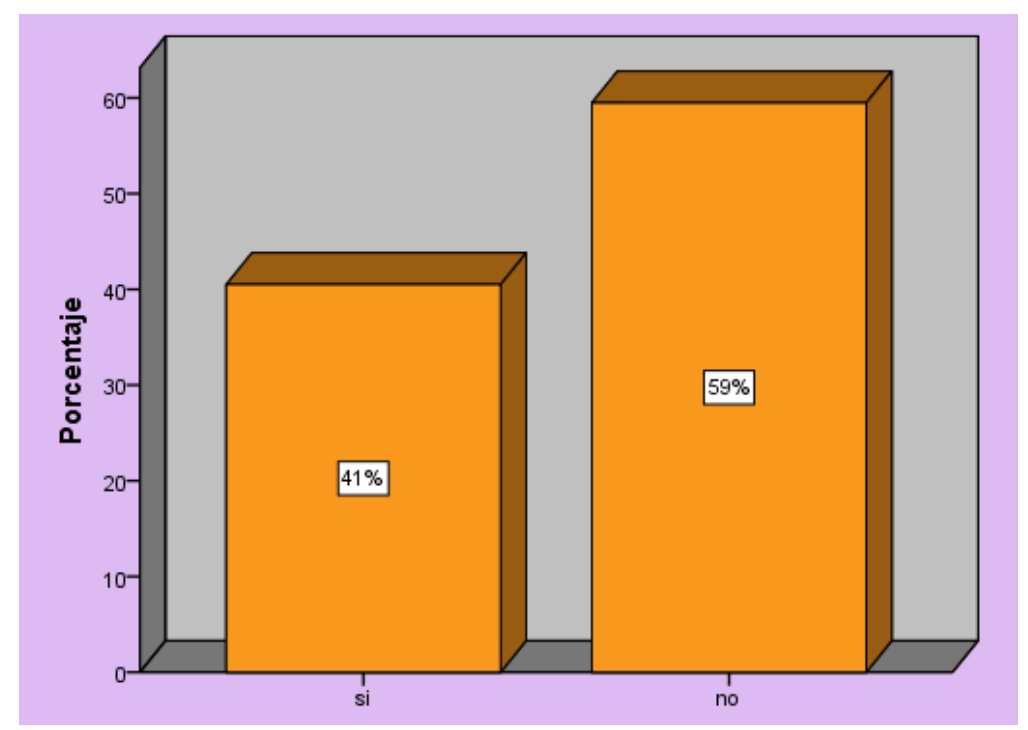

Fuente: Elaboración propia.

Interpretación: Al preguntarles a los encuestados si conocían los beneficios del café, el 
$41 \%$ afirmaron que si conocen; y el 59\% no conocen.

\section{Gráfico 6. Momento del día que toma café}

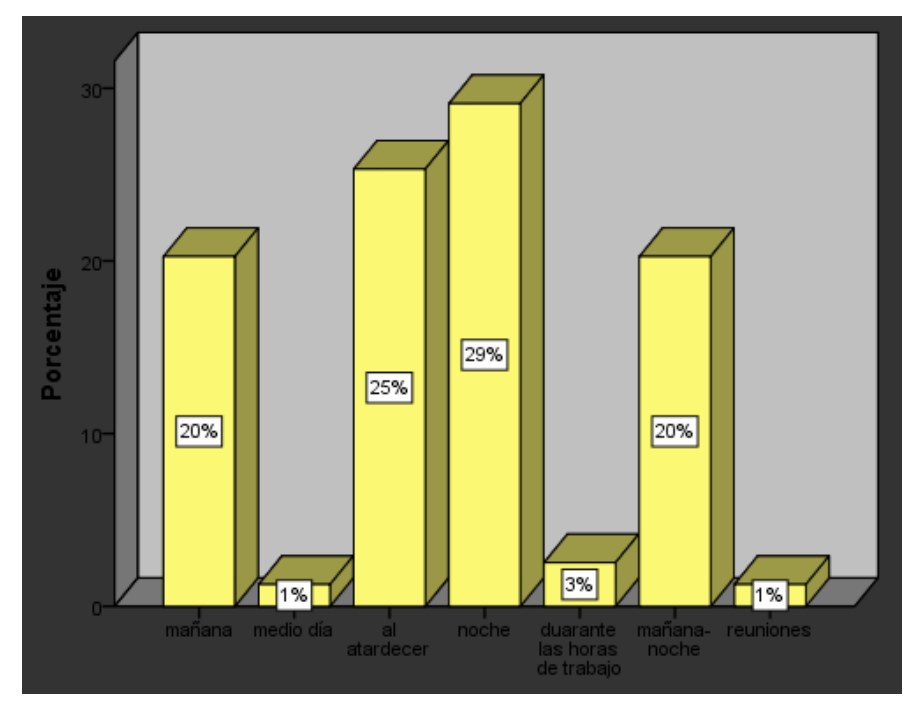

Fuente: Elaboración propia.

Interpretación: Al indagar a las 362 personas encuestadas sobre el momento del día en que toman café, respondieron: Un 20\% toman en la mañana, 1\% al mediodía, 25\% al atardecer, $29 \%$ en la noche, $3 \%$ en reuniones.

\section{Gráfico 7. Frecuencia de tomar café}

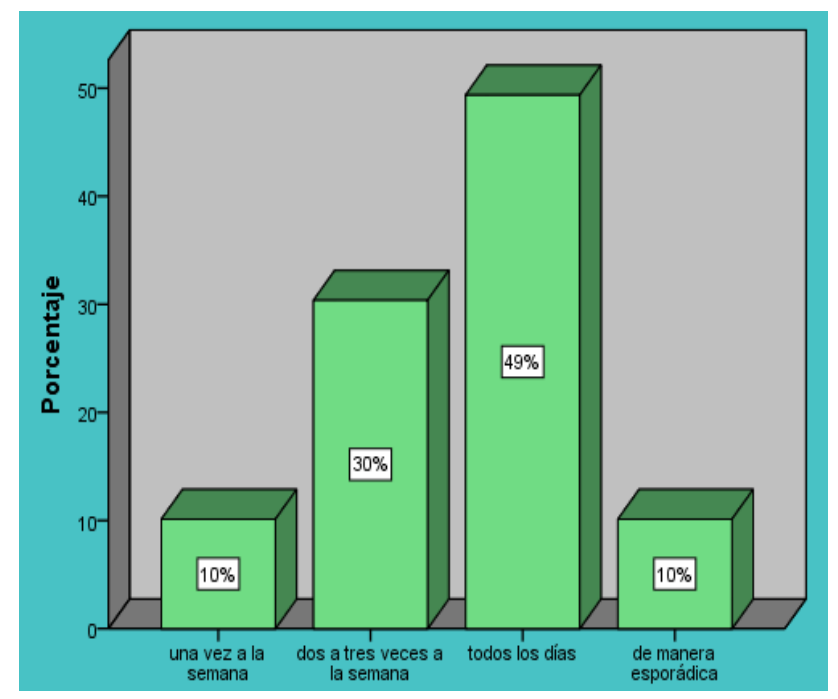

Fuente: Elaboración propia. 
Interpretación: Al preguntarle al total de personas encuestadas, con qué frecuencia toman café respondieron: que el 10\% tomaban una vez a la semana, el 30\% de dos a tres veces por semana, 49\% manifestaron que tomaban todos los días, y el 10\% de manera esporádica.

\section{Gráfico 8. Cantidad de café que toma}

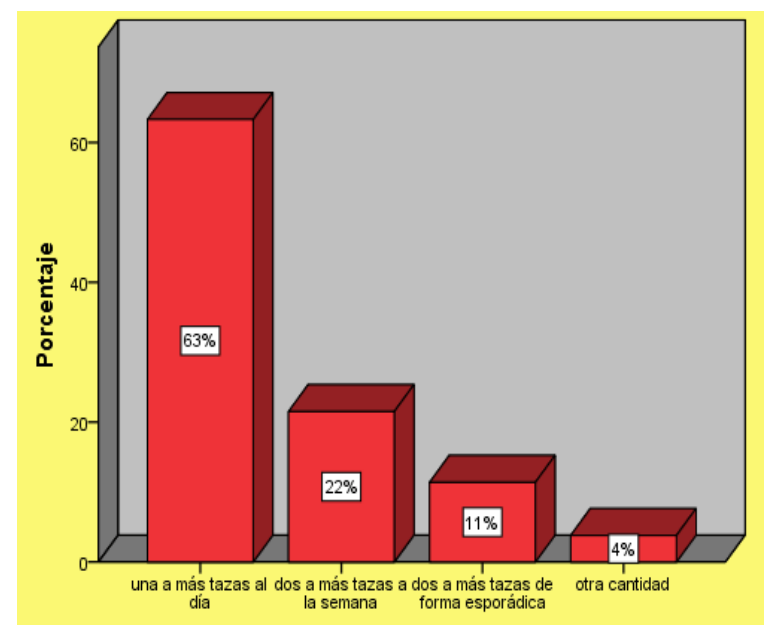

Fuente: Elaboración propia.

Interpretación: Cuando se les preguntó a las personas encuestadas sobre la cantidad de café que tomaban, manifestaron: que el 63\% tomaban de una a más tazas al día, el 22\% toman de dos a más tazas a la semana, el ll\% indicaron que toman de dos a más tazas de forma esporádica, y el $4 \%$ toman otra cantidad.

Gráfico 9. Marca de café preferida

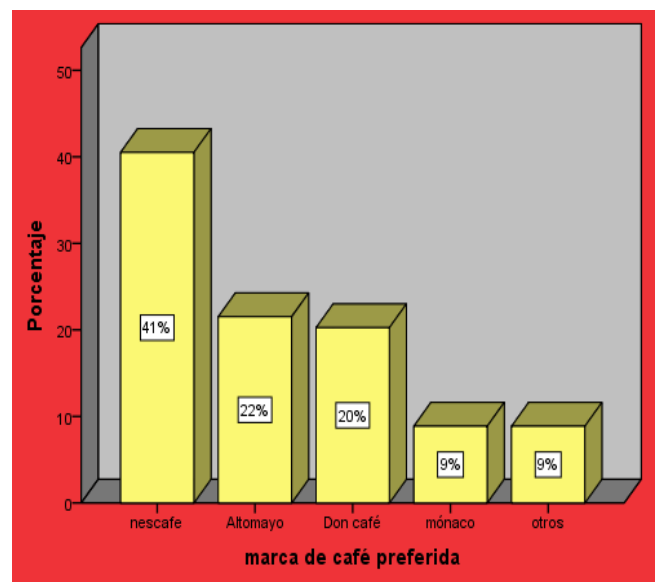

Fuente: Elaboración propia 
Interpretación: Del 100\% de encuestados, cuando se les preguntó sobre la marca de su preferencia, respondieron: el $41 \%$ prefieren la marca Nescafé, un 22\% se inclinan por la marca Altomayo, el 20\% optaron por la marca de Don Café, el 9\% manifestaron que preferían la marca Mónaco y un 9\%prefieren otras marcas.

\section{Gráfico 10. Lugar preferido que toma café}

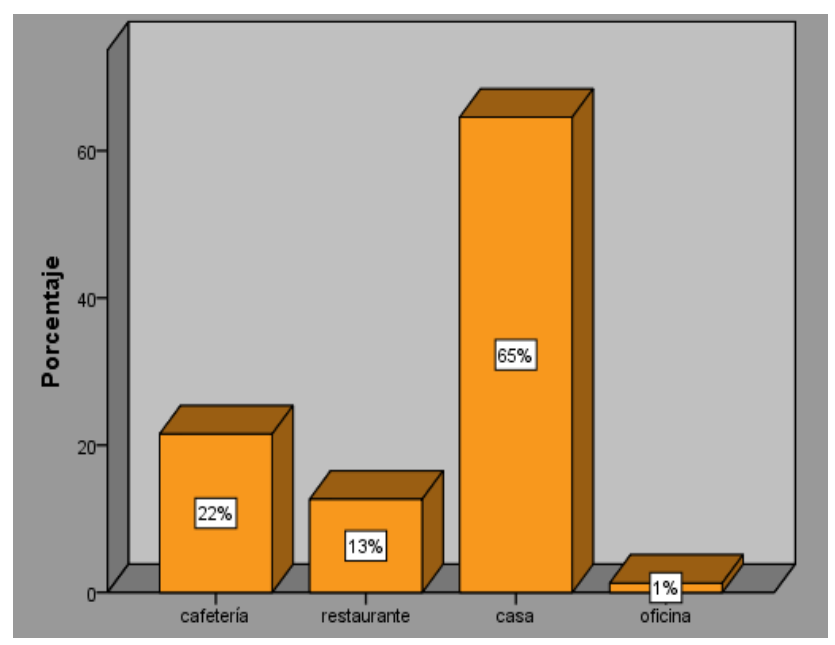

Fuente: Elaboración propia.

Interpretación: Al preguntarles a las 362 personas encuestadas cuál es el lugar de su preferencia para tomar café, el 22\% manifestó que toma en la cafetería, un 13\% lo hace en el restaurante, el 65\% consume en su hogar y sólo el 1\% toma en la oficina.

\section{Gráfico 1l. Precio que está dispuesto a pagar}

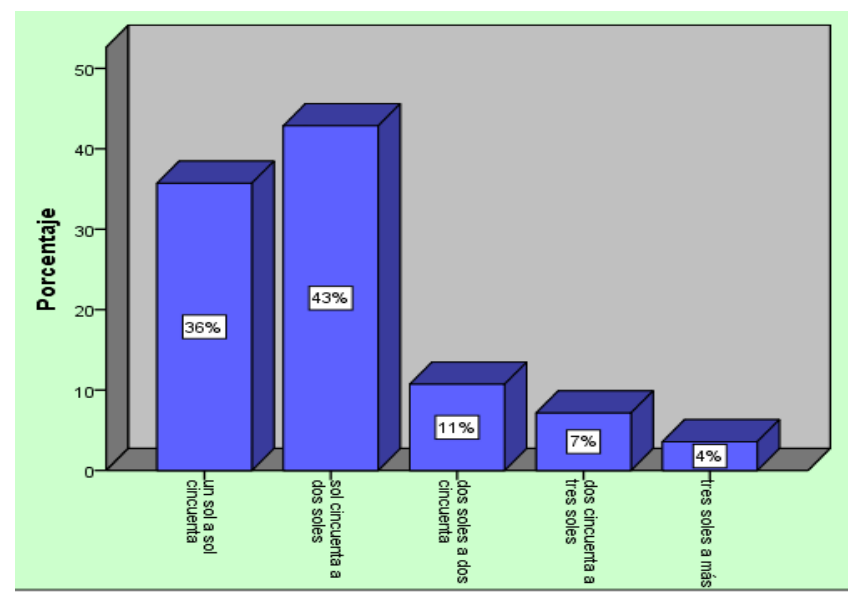

Fuente: Elaboración propia. 
Interpretación: Cuando se les preguntó a las personas, por el precio que pagarían por una taza de café, el 36\% paga de S/.1 a S/.1.50; el 43\% pagarían de S/.1.50 a S/.2; un 11\% pagan de S/.2 a S/.2.50; el 7\% de los encuestados están dispuestos a pagar de $\mathrm{S} / .2 .50$ a S/.3, y el $4 \%$ pagan de S/.3 tres a más.

\section{Gráfico 12. Calidad de café que ofrecen las cafeterías}

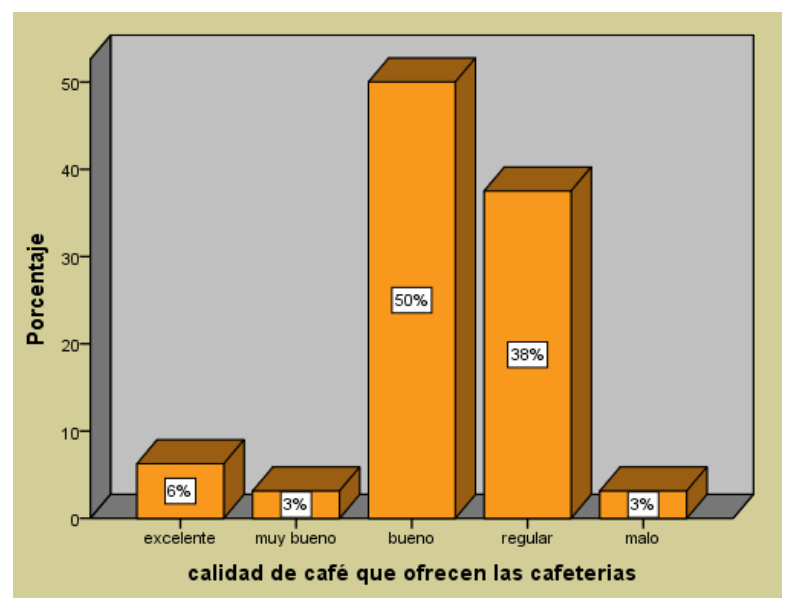

Fuente: Elaboración propia.

Interpretación: Del 100\% de encuestados, el 6\% calificó como excelente el café que ofrecen las cafeterías del distrito de Chota; un 3\% muy bueno; el 50\% manifestaron que es bueno, el 38\% regular; y el 3\% dijeron que es malo.

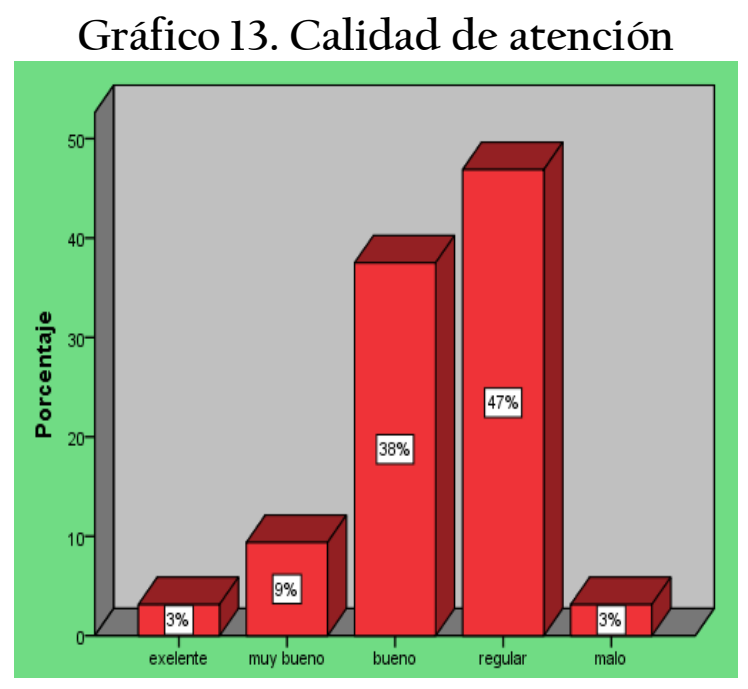

Fuente: Elaboración propia. 
Interpretación: A las 362 personas encuestadas se les indagó sobre la calidad de atención que brindan las cafeterías del distrito Chota: el 3\% contestaron que la atención es excelente, el 9\% muy bueno, un 38\% bueno, el 47\% indicaron que la atención es regular y un 3\% manifestó que es malo.

\section{Gráfico 14. Medios de comunicación para informarse}

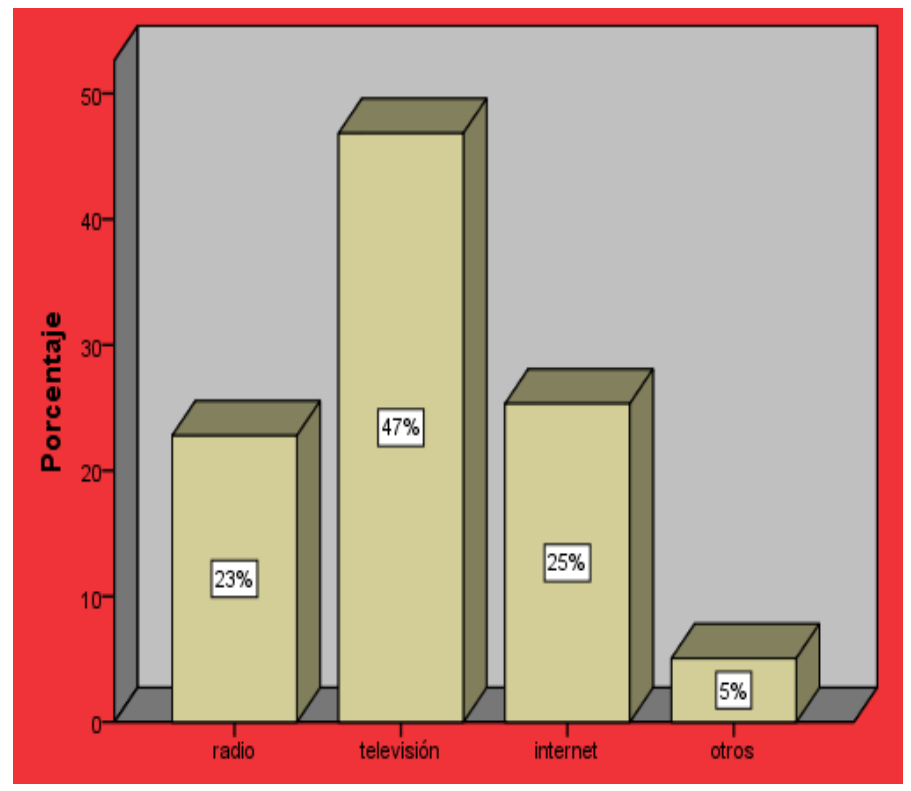

Fuente: Elaboración propia.

Interpretación: Del 100\% de encuestados, el 23\% indicaron que les gustaría informarse de los beneficios del café por intermedio de la radio, el $47 \%$ por la televisión, un $25 \%$ por el internet y un 5\% prefieren informarse por otros medios de comunicación.

3.2. Objetivo específico 2: Elaborar estrategias de Marketing para mejorar el consumo de café en el distrito de Chota.

3.2.1. FODA: Según Espinoza (2013), la matriz FODA es una herramienta estratégica de análisis interno y externo, de la situación de una empresa: su objetivo es ofrecer un claro diagnóstico para poder tomar las acciones estratégicas oportunas y mejorar en el futuro. Por sus iniciales, FODA significa: fortalezas, oportunidades, debilidades y amenazas. 
Tabla 4. Análisis interno

\begin{tabular}{|c|c|}
\hline $\begin{array}{c}\text { FORTALEZAS } \\
\end{array}$ & DEBILIDADES \\
\hline $\begin{array}{l}\text { Brinda beneficios para la salud. } \\
\text { Experiencia de las personas que ofertan el } \\
\text { producto. } \\
\text { Disponibilidad de materia prima de buena } \\
\text { calidad y precios accesibles. } \\
\text { Se cuenta con locales de venta propios. } \\
\text { El recurso humano que oferta el producto } \\
\text { es emprendedor y dispuesto al cambio. } \\
\text { Los locales de venta que ofertan café } \\
\text { cuentan con servicios de comunicación } \\
\text { instalados. } \\
\text { Las cafeterías brindan seguridad y } \\
\text { confianza. }\end{array}$ & $\begin{array}{l}\text { Los locales que ofertan café de la zona } \\
\text { urbana del distrito de Chota no cuentan } \\
\text { con un plan estratégico de marketing. } \\
\text { El café que se ofrece en el distrito de Chota } \\
\text { no es de la mejor calidad. } \\
\text { No se cuenta con medios de publicidad } \\
\text { para promocionar el producto. } \\
\text { Falta de presupuesto para participar en } \\
\text { ferias, rondas de negocio y capacitaciones } \\
\text { a nivel local, regional, nacional. } \\
\text { Falta de capacitación a personal de ventas- } \\
\text { pos ventas. } \\
\text { Las cafeterías no cuentan con buena } \\
\text { distribución del producto. } \\
\text { No se cuenta con planes de contingencia } \\
\text { (luz, agua, entre otros.) }\end{array}$ \\
\hline
\end{tabular}

Fuente: Elaboración propia.

Tabla 5. Análisis externo

\begin{tabular}{|c|c|}
\hline OPORTUNIDADES & AMENAZAS \\
\hline $\begin{array}{l}\text { Estabilidad política y democrática. } \\
\text { Existencia de tratados de libre comercio } \\
\text { para la adquisición de tecnología. } \\
\text { Intervención de PROM - PERÚ, Sierra y } \\
\text { Selva Exportadora. } \\
\text { Clima adecuado para la producción y } \\
\text { comercialización del café. } \\
\text { Se cuentan con vías de comunicación } \\
\text { accesible. } \\
\text { Acceso a entidades financieras. } \\
\text { Clima adecuado para consumir café. } \\
\text { Incremento de los ingresos económicos } \\
\text { de la población. } \\
\text { Crecimiento demográfico de la población }\end{array}$ & $\begin{array}{l}\text { Cambio de gobierno e inestabilidad } \\
\text { política. } \\
\text { Cambios climáticos que afectan la } \\
\text { producción y comercialización de café. } \\
\text { Presencia de plagas y enfermedades en } \\
\text { los cultivos. } \\
\text { Fuertes campañas publicitarias de las } \\
\text { empresas que ofrecen productos } \\
\text { sustitutos. } \\
\text { Publicidad engañosa o fraudulenta, } \\
\text { desprestigiando los atributos del } \\
\text { producto. }\end{array}$ \\
\hline
\end{tabular}

Fuente: Elaboración propia. 
En la presente investigación se ha segmentado la población del distrito de Chota de acuerdo al nivel socioeconómico, sabiendo que el 3,5\% de la población pertenece al nivel AB; el 8,8\% pertenece al nivel socioeconómico C; un 15,4\% pertenece al nivel D; y el 72,3\% en el nivel E (Departamento de Estadística-CPI, 2016).

\subsubsection{Estrategia diferenciada}

Nos dirigimos a los diferentes segmentos del mercado que se ha identificado, pero con una oferta y estrategia diferente para cada una de ellos; es decir que de acuerdo con los niveles socioeconómicos de la población, se debe ofrecer un tipo de café para cada segmento, clasificándolo de acuerdo a la calidad. Para el segmento AB se debe ofrecer café Gourmet, para el nivel socioeconómico C se debe ofertar café orgánico, para el nivel D un café de calidad ecológica, y para el nivel E, se debe ofertar café de calidad convencional o comercial.

\subsubsection{Estrategias de marketing de posicionamiento}

Es el espacio que ocupa el producto en la mente de los consumidores. Mediante esta estrategia, se busca posicionar el producto en la mente de los consumidores con el posicionamiento inrish. La estrategia a desarrollar es dar a conocer a los consumidores que el café es un alimento de origen vegetal que contiene químicos naturales, con propiedades similares a las frutas y verduras; aunque no es una fuente de nutrientes ni de calorías, el café tiene más de mil sustancias químicas naturales, muchas de ellas con capacidad antioxidante, ayuda a eliminar los radicales libres, es decir, es un producto anticancerígeno, de tal manera que el café tiene beneficios para la salud; es importante resaltar el efecto estimulante que tiene la cafeína en aquellas personas que realizan largas jornadas de trabajo, o aquellas que requieren mejorar su nivel de concentración.

\subsubsection{Estrategia por calidad y precio}

El mecanismo a implementar estará en función de los gustos y preferencias del consumidor y de acuerdo al estatus social. La estrategia por calidad y precio será: un café de mejor calidad un mayor precio, y un café convencional con un menor precio. 


\subsubsection{Estrategias de crecimiento}

Para mejorar el consumo de café en la zona urbana del distrito de Chota se tendrá como referencia a dos de las aristas de la Matriz de Ansoff: productos actuales en mercado actual, productos nuevos en mercado actual (Tabla 6).

Tabla 6. Matriz de Ansoff

\begin{tabular}{|c|c|c|c|}
\hline & \multicolumn{3}{|c|}{ PRODUCTOS } \\
\hline & & ACTUALES & NUEVOS \\
\hline \multirow{2}{*}{ MERCADO } & ACTUAL & $\begin{array}{c}\text { Penetración del } \\
\text { mercado }\end{array}$ & $\begin{array}{l}\text { Desarrollo de } \\
\text { productos }\end{array}$ \\
\hline & NUEVOS & $\begin{array}{l}\text { Desarrollo de } \\
\text { mercados }\end{array}$ & Diversificación \\
\hline
\end{tabular}

Fuente: Ansoff (1957)

\subsubsection{Estrategia por Atributos}

El café peruano es un café de la especie arábica, cultivado en 13 regiones del Perú. Es una bebida suave, de taza limpia, con un grado de acidez, con un cuerpo medio/alto, de excelente aroma y con un sabor agradable; en conclusión, el café peruano es un café de alta calidad, y la estrategia será dar a conocer al público consumidor las cualidades y atributos de este café.

\subsubsection{Estrategia funcional o las 4ps del Marketing}

Estrategia de Producto: El café que se debe ofrecer será de buena calidad, con sus atributos sensoriales más importantes, en sus diferentes marcas, calidades, presentaciones; con la finalidad de satisfacer las necesidades de los diferentes niveles socioeconómicos de la población. En efecto, al momento de hacer el estudio de mercado, un alto porcentaje de encuestados pedían mejor calidad del producto. La estrategia será, ofrecer productos de alta calidad, garantizados, que sus características y presentaciones estén acordes a los gustos y preferencias de los demandantes. 
Estrategia de Precio: El precio estará fijado de acuerdo a los ingresos de todos los niveles socioeconómicos de la población, teniendo en cuenta la calidad y marca del producto, con el fin de cubrir las expectativas de todos los estatus sociales del público consumidor, es decir, que la estrategia a utilizar referente al precio, estará en función a los diferentes ingresos de la población, en alusión al estudio de mercado.

Estrategia de Distribución o Plaza: Los locales que oferten el producto deberían almacenarlo de forma adecuada, manejando correctamente sus inventarios y gestión de pedidos; sus locales de ventas estarán ubicados en puntos estratégicos. La distribución del producto tendrá la estrategia de distribución utilizando con eficiencia los canales indirectos, es decir, el producto sale de la empresa al mayorista, luego llega al minorista y este distribuye al consumidor final. Como se aprecia en el Gráfico 15.

\section{Gráfico 15. La distribución del producto}

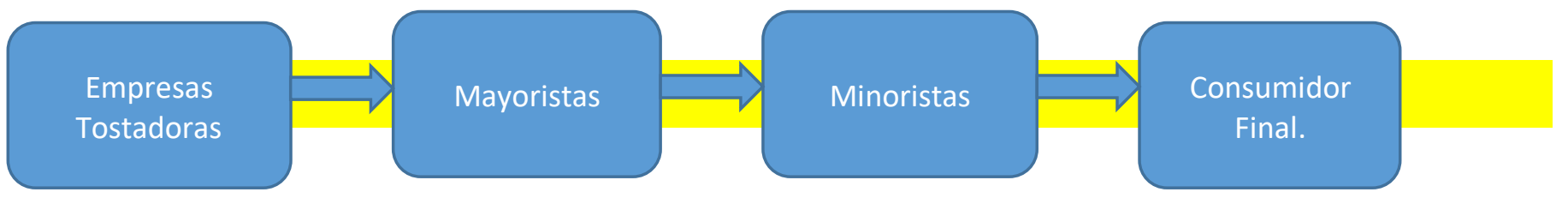

Fuente: Elaboración propia.

Estrategia de Promoción: Mediante esta estrategia se informará de los beneficios, bondades, atributos del café. La estrategia a utilizar incluye lanzar publicidad a través de los importantes medios de comunicación, con un spot publicitario dando a conocer las características, propiedades y beneficios del producto, con el fin de desterrar los mitos según los cuales el café daña la salud. Los medios a utilizar serán la televisión, la radio, el internet, redes sociales y otros, tal como recomiendan las personas encuestadas en el momento de hacer el estudio de mercado.

\section{Discusión}

Los resultados de la investigación corroboran lo expuesto por Tepox-Vivar \& GonzálezCabañas (2021): "al margen de sus transformaciones, el comercio justo ostenta el mérito de colocar en la mesa de debate la necesidad de cuestionar y repensar los valores movilizados en las 
relaciones comerciales basadas en la maximización de la ganancia, y que dejan de lado el desarrollo de capacidades y empoderamiento de los pequeños productores".

Además, los resultados coinciden con Cuevas (2020) quien afirma que es importante promover el involucramiento de organizaciones de la sociedad civil, el sector público y privado e instituciones de investigación en el proceso de posicionamiento de rubros ofertados por pequeños productores.

\section{Conclusiones}

Las estrategias de marketing si mejoran el consumo de café en el distrito de Chota, pero estas estrategias de marketing necesitan ser efectuada bajo una excelente coordinación de marketing, tanto el gobierno, como por las empresas tostadoras.

El 41\% de los encuestados prefieren la marca Nescafé, un 43\% de todos los encuestados están dispuestos a pagar de S/.1.50 a S/.2.00, el 65\% del total de personas encuestadas toman café en su casa, y el $47 \%$ de encuestados prefieren informarse sobre los beneficios que brinda el café a través de la televisión.

Los dueños de las cafeterias, afirmaron que nunca han tenido el apoyo del gobierno y de ninguna otra institución para fortalecer su emprendimiento; también pusieron mucho énfasis y manifestaron que es muy importante la capacitación a los trabajadores para mejorar el nivel de atención al cliente y por último, dijeron que ellos nunca aplican ninguna estrategia para mejorar el consumo.

\section{Referencias}

Ansoff, I. (1957). Estrategias para la Diversificación, Harvard Business Review.

Castañeda, E. (2000). El ABC del Café: Cultivando Calidad. Perú: Tecnatrop S.R.L. Recuperado de https:/tecnatrop.com/el-abc-del-cafe-cultivando-calidad/

Cruz Estrada, Isaac. (2018). Aplicación de la mercadotecnia relacional en una empresa de venta de café de Baja California. Región y sociedad, 30(71) https://doi.org/10.22198/rys.2018.71.a392

Cuevas Albarrán, Valeria Betzabé. (2020). Aplicación del etnomarketing para la comercialización sostenible de pequeños productores. Pensamiento \& Gestión, (48), 195-222. Epub May 10, 2021. Retrieved August

19 , 2021, from 
REVISTA DE LA UNIVERSIDAD DEL ZULIA. 3ㄹ época. Año 12 N³4, 2021

Abel Salcedo Herrera et al. /// Propuesta de estrategias de marketing para mejorar el consumo de café, 76-96 DOI: http://dx.doi.org/10.46925//rdluz.34.06

http://www.scielo.org.co/scielo.php?script=sci_arttext\&epid=S1657$62762020000100195 \& \operatorname{lng}=$ en\&tlng=es.

Departamento de Estadística - CPI http://www.cpi.pe/market/estadistica-poblacional.html

(2016). Recuperado de Espinoza, R. (2013). La Matriz y Análisis Foda. Universidad de Ciencias Aplicadas. Lima.

Espinoza, R. (2015). Estrategias de Marketing, Tipos y Ejemplos. Universidad de Ciencias Aplicadas. Lima.

Federación Nacional de Cafetaleros en Colombia (2016). Promoción del consumo Toma Café. Recuperado de https://federaciondecafeteros.org

García, N. (2010). El Consumo sirve para pensar. Universidad Mesoamericana Oaxaca- México. Recuperado de https://dialnet.unirioja.es/servlet/articulo?codigo=2700957

Hernández, C. G.; Hurtado Hurtado, J. (2020). Escenarios prospectivos pospandemia para la internacionalización del sector agroalimentario de Ecuador al año 2035, Revista de Estudios Políticos y Estratégicos, 8-2: 36-66.

Junta Nacional del Café (2016) Consumo Per-Cápita del café en el Perú. Recuperado de https://www.minagri.gob.pe/portal/download/2017/pncafe/sector-cafe-peru.pdf

Kotler, P. (2006). Dirección de Marketing. Duodécima edición, Tecnológico de MonterreyCampus Estado de México.

Minagri (2016), El cultivo de café es el sustento de 223 mil familias. Recuperado de https://www.minagri.gob.pe/portal/download/2017/pncafe/cafe-peruano-motor-desarrollo.pdf

Naupas, H. (2013). Metodología de la investigación Científica y elaboración de tesis. Recuperado de https:/download.e-bookshelf.de/download/0003/5873/05/L-G-0003587305-0006913492.pdf

Perea, J., \& Rivas, L. (2008). Estrategias competitivas para los productores cafetaleros de la región de Córdoba, Veracruz, frente al mercado mundial. Contaduría y administración, (224), 9-33. Recuperado de http://www.scielo.org.mx/scielo.php?script=sci_arttext\&epid=S0186$10422008000100002 \& \operatorname{lng}=$ es\&tlng=es.

Reuters, J. (2016), Demanda global de café se desacelera y consumo en Brasil pierde ritmo de crecimiento. Revista América Economía.

Rodríguez, F. (2016), Desarrollo del Consumo del Café. Diario la Nación. Recuperado de https://www.lanacion.com.ar/lifestyle/12-beneficios-del-cafe-que-seguro-no-conocias$\operatorname{nid} 2131512$

Ruiz, S. (2002). Café Antioxidantes y Protección de la Salud. Instituto de Ciencias Médicas Villa 
Clara - Cuba.

Tepox-Vivar, Ángeles \& González-Cabañas, Alma Amalia. (2021). Una nueva apuesta de los cafeticultores chiapanecos. La estrategia del símbolo de pequeños productores. LiminaR, 19(1), 195-208. Epub 02 de marzo de 2021.https://doi.org/10.29043/liminar.v19il.815

Salazar, R. (2004). Principales autores de estrategia empresarial, Universidad Nacional de Educación, Facultad de Ciencias Administrativas. Lima. 